\title{
OS ARQUIVOS E A SÉTIMA ARTE
}

\author{
THE ARCHIVES AND THE SEVENTH ART
}

\author{
Fernanda Kieling Pedrazzi ${ }^{1}$ e Paulo Henrigue Trennepohl ${ }^{2}$
}

Recebido em: 12/04/2016

Aprovado em: 04/10/2016

\section{RESUMO}

Este trabalho apresenta uma forma pouco convencional de mostrar como são abordados os arquivos: por meio de um estudo de audiovisuais comerciais, relacionando o cinema e a arquivologia. Nesta pesquisa, apresenta-se de que modo são apresentados ao grande público os arquivos e acervos documentais ligados à temática da religiosidade. A escolha dos filmes analisados ocorreu com base em uma listagem divulgada pelo Arquivo Público do Rio Grande do Sul (APERS), sendo selecionados os filmes com maior incidência no site de busca Google. Após, utilizou-se como segundo critério de seleção a presença da temática religiosa, sendo selecionados para análise dois filmes: "Anjos e Demônios" e "O Nome da Rosa". A análise foi feita abordando o arquivo, o acesso, a preservação e a conservação de documento em ambos os filmes selecionados, mostrando a importância dessas temáticas e do profissional arquivista junto a uma organização. Por meio da pesquisa, foi possível constatar que o profissional presente junto ao acervo é de grande importância, mas que existe uma distorção das atribuições de um arquivista, havendo dúvida com relação à atuação de arquivistas e bibliotecários.

Palavras-chave: Análise; Arquivologia; Cinema; Religião.

\begin{abstract}
This paper presents an unconventional way of showing how the files are approached through a study of audiovisual commercial, relating film and archives. This research presents the way how are presented to the public archives and collections of documents, related to the theme of religion. The choice of films analyzed is given from a list published by APERS and as selection criteria were considered films with a higher incidence of the Google search site. After it was used as a second criterion for selection to the religious theme we have chosen to work with two films "Angels and Demons" and "The Name of the Rose". The analysis was done addressing the file, access, preservation and conservation of document in both films selected, showing the importance of the themes and professional Archivist with the organization. Through research it was possible to observe how are subjects selected for observation and it was established that the professional with the present collection is of great importance, but there is a distortion of the duties of an archivist, there is doubt about the performance of archivists and librarians.
\end{abstract}

Keywords: Analysis; Archivology; Movies; Religion.

1 Professora Adjunta da Universidade Federal de Santa Maria (UFSM) no Departamento de Documentação do Centro de Ciências Sociais e Humanas (CCSH). Doutora em Letras pela UFSM. Possui graduação em Comunicação Social - Jornalismo pela UFSM, graduação em Arquivologia pela UFSM e mestrado em Engenharia de Produção pela UFSM. E-mail: fernanda.pedrazzi@gmail.com

2 Bacharel em Arquivologia pela Universidade Federal de Santa Maria (UFSM). Acadêmico do Curso de Psicologia da Faculdade Integrada de Santa Maria (FISMA). E-mail: paulohenrique2706@uol.com.br 


\section{Introdução}

Este artigo, intitulado "Os arquivos e a Sétima Arte", originou-se de um Trabalho de Conclusão de Curso (TCC), que buscou, por meio de um estudo de audiovisuais, relacionar o cinema com a arquivologia. A escolha desse tema ocorreu por interesse pessoal na sétima arte e por um envolvimento, ao longo da graduação, com um projeto de extensão que utiliza o cinema como meio de promover a educação e a cidadania. A esse respeito, é importante ressaltar que o conceito de cinema como sétima arte é empregado pela primeira vez por Ricciotto Canudo ${ }^{3}$ no ano de 1912.

Para o desenvolvimento do estudo proposto, a problematização da pesquisa voltou-se à seguinte questão: como é apresentado ao grande público o mundo dos arquivos por meio do cinema? A fim de responder a essa questão, estabeleceram-se três objetivos específicos: reconhecer que elementos são destacados em filmes na representação do mundo dos arquivos; analisar, à luz da arquivologia, as temáticas referentes ao fazer arquivístico que são apresentados ao grande público; e refletir acerca da imagem veiculada sobre documentos, arquivos e arquivistas para o senso comum por meio da sétima arte.

\section{Referencial teórico}

Para fundamentar este estudo, apresenta-se a seguir uma revisão teórica abordando assuntos que envolvem cinema e arquivos.

\subsection{Os arquivos}

$\mathrm{O}$ termo arquivo surgiu entre o século III e II a.C. na Grécia antiga. De arché evoluiu para archeion ou archivum, significando local de guarda ou depósito de documentos. Os arquivos, desde seu princípio, estiveram ligados ao poder, sendo criados para servir à 3 Disponível em: <http://fgimello.free.fr/enseignements/metz/textes theoriques/canudo.htm>. Acesso em: 22 maio 2013. classe dominante, pois resguardavam seus direitos, mantendo, consequentemente, seu poder.

De acordo com o Dicionário Brasileiro de Terminologia Arquivística (2005), arquivo é um conjunto de documentos produzidos por uma entidade coletiva, pública ou privada, ou por um indivíduo, no desempenho de suas atividades, independentemente do suporte. Além disso, pode ser uma instituição ou um serviço que tem como finalidade a custódia, o processamento técnico e a conservação de documentos, bem como o acesso a eles. Um arquivo pode ser, ainda, o móvel destinado à guarda de documentos. Rousso (1996) explicita que o arquivo pode ser escrito, oral ou filmado, sendo produto de uma linguagem própria, que parte de um indivíduo singular, mas que pode demonstrar o ponto de vista de um coletivo.

Rondinelli (2002) destaca que os arquivos passaram por cinco marcos significativos. $\mathrm{O}$ primeiro foi em 1789-1790, com Revolução Francesa e a criação do Arquivo Nacional da França. Ambos os fatos foram responsáveis pelo reconhecimento da importância dos documentos, da responsabilidade do Estado por sua guarda e conservação e da abertura do arquivo ao público.

$\mathrm{O}$ segundo momento ocorreu em 1821, também na França, com a criação da École Nationale des Chartes, transformando a arquivologia em uma ciência que auxilia a história e fazendo com que despertasse o interesse pelo valor histórico dos arquivos e dos documentos. Já o terceiro marco aconteceu no ano de 1841, na França, quando Natalis Du Wailly, arquivista e historiador, definiu que os documentos fossem organizados por fundos. Nesse momento, surgiram então os princípios de respeito aos fundos e da proveniência, que, a partir do ano de 1898, tornaram-se, juntamente com o Manual dos Holandeses, um dos pilares da teoria arquivística, orientando a organização dos arquivos até os dias de hoje. 
Após a Segunda Guerra Mundial, final de 1945, foi que se estabeleceu o quarto marco, com o aumento da massa documental em decorrência dos acordos e tratados produzidos pela administração pública. Nesse momento, nasceu a gestão dos documentos, visando à racionalização dos procedimentos arquivísticos por meio do estabelecimento de um conjunto de procedimentos técnicos referentes à produção, ao uso, à avaliação e ao arquivamento dos documentos em fase corrente e intermediária, tendo em vista sua eliminação ou seu recolhimento para guarda permanente.

Atualmente, estamos vivenciando o quinto marco arquivístico, que teve seu início em 1980, quando passaram a ser socialmente difundidos os documentos eletrônicos.

\subsubsection{Arquivos eclesiásticos}

Hayes (2005 apud SANTOS, 2005, p. 42) define arquivos eclesiásticos como

uma coleção de documentos, registros, escrituras e petições relativos à origem, à fundação, ao crescimento, à história, aos direitos, aos privilégios, e às constituições de uma diocese, de uma paróquia, de um mosteiro, ou de uma comunidade religiosa sob a jurisdição da igreja; o termo é aplicado também ao lugar ou ao depósito onde tais registros e originais são mantidos.

Os documentos relativos à diocese e às paróquias devem ser guardados com o máximo de cuidado. Por isso, em cada cúria, deve haver um lugar seguro, isto é, um arquivo diocesano, no qual sejam guardados, dispostos em ordem certa e diligentemente fechados os instrumentos e escritos que se referem às questões diocesanas espirituais e temporais. Essas instruções estão contidas no Código de Direito Canônico (CDC) ${ }^{4}$. 4 O Código de Direito Canónico (CDC) é o conjunto ordenado das normas jurídicas do direito canônico que regula a organização da Igreja Católica Romana, a hierarquia do seu governo, os direitos e as obrigações dos fiéis e o conjunto de sacramentos e sanções que se estabelecem pela contravenção das mesmas normas. Na prática, é a Constituição da Igreja dos artigos nos textos legislativos civis.
Santos (2005) aponta três tipos principais de arquivos eclesiásticos ou religiosos: o arquivo arcebispal (conhecido também como arquivo arquiepiscopal), os arquivos episcopais ou diocesanos e os arquivos paroquiais. Assim, com base nos exemplos dados por Santos (2005), percebe-se que a Igreja, especialmente a católica, conserva a documentação produzida e recebida referente ao seu governo espiritual e temporal.

\subsection{2 $\mathrm{O}$ arquivo do Vaticano ${ }^{5}$}

O Arquivo Secreto do Vaticano está localizado na Itália, em uma das sete colinas de Roma. Sua criação ocorreu por volta do ano de 1610 pelo Papa Paulo V, com finalidade de guardar não apenas o legado de Jesus Cristo, mas também a história da Igreja Católica, seja por meio de documentos, cartas ou decretos, por exemplo.

Segundo a Igreja Católica (1988, p. 11 apud SANTOS, 2005, p. 65), esse arquivo foi normalizado pelo artigo 187 da constituição Apostólica Pastor Bonus, nos seguintes termos:

são conservados os documentos relativos ao governo da Igreja, para antes de tudo estarem à disposição da Santa Sé e da Cúria no desempenho do próprio trabalho, e para que depois, por concessão pontifícia, possam representar para todos os estudiosos de história fontes de conhecimento, mesmo profano, daquelas regiões que há séculos estão intimamente ligadas com a vida da Igreja.

A massa documental do Arquivo Secreto do Vaticano é composta de cerca de doze séculos, abrangendo mais de 600 fundos arquivísticos distribuídos em mais de 85 quilômetros de prateleiras. Algumas dessas prateleiras estão no Bunker, um cofre subterrâneo de dois andares abaixo do Cortile della Pigna, um dos Museus do Vaticano.

5 Disponível em: $<$ http://www.archiviosegretovaticano.va/content/archiviosegretovaticano/it.html>. Acesso em: 09 jun. 2013. 
Os documentos estão divididos em seis grupos documentais: Cúria, Delegações Papais, Singulares ou Familiares, Concílios, Ordens Religiosas, Mosteiros e Confrarias e Outros. O Arquivo Secreto do Vaticano abriga uma biblioteca, um laboratório de restauração, uma sala de estudos secretos, um laboratório de fotografias digitais, um laboratório de informática e um espaço administrativo.

No ano de 1881, o então Papa Leão XIII liberou o acesso do Arquivo Secreto do Vaticano para estudantes e pesquisadores, o que tornou este um dos mais famosos centros de pesquisas da história mundial. Em 1924, foram liberados documentos do período de 1846 até 1922. Em junho de 2006, o Papa Bento XVI autorizou a abertura de todos os arquivos do Vaticano durante o pontificado do Papa Pio XI (1922-1939), um período da história compostos de documentos que dizem respeito às relações entre $o$ Vaticano e a Alemanha nazista.

Quanto ao acesso ao Arquivo Secreto do Vaticano, a Igreja Católica adotou políticas, tais como: estudantes universitários não têm acesso; somente tem acesso pesquisadores qualificados com diploma universitário; e somente é permitido acesso aos documentos produzidos até fevereiro de 1939.

\subsubsection{O profissional arquivista}

O profissional graduado em Arquivologia tem em sua formação noções de varias áreas do conhecimento, como História, Direito, Informática, Administração, Contabilidade, Comunicação e Paleografia. A Arquivologia busca cada vez mais o aperfeiçoamento e aprofundamento de seus estudos, devido às mudanças na área da Tecnologia da Informação que impactam os acervos dos arquivos.

Como a informação está cada dia mais presente no mundo, os profissionais que atuam nessa área passam a ganhar destaque como facilitadores do acesso à informação. Com uma vasta área de atuação no mercado de trabalho, o profissional arquivista tem várias atribuições, incluindo: a seleção, o arranjo, a descrição, a preservação, a conservação e a reprodução de documentos.

$\mathrm{O}$ arquivista atua, assim, na guarda, na conservação, na organização, no controle, na administração e na recuperação da informação registrada, ou seja, na gestão documental, em empresas privadas e instituições públicas, centros de documentação, fundações, organizações não governamentais (ONGs), universidades, arquivos históricos, centros de memória e museus que tenham departamentos de documentação histórica, por exemplo.

Atuando como profissional da informação, como pode ser designado, representa múltiplas competências e habilidades, devendo ter qualificações pessoais e profissionais, no intuito de propiciar um trabalho de qualidade em qualquer meio de que faça parte. $\mathrm{O}$ arquivista assume uma função importante para a sociedade por ter a informação como seu objeto de estudo - o documento e a informação nele registrada podem e, em alguns casos, devem ser preservados a fim de manter a possibilidade de revisitar a história e acender a memória, seja ela de uma instituição, de um povo ou de uma pessoa.

\section{$2.2 \mathrm{O}$ cinema}

O primeiro filme cinematográfico público e pago foi apresentado em dezembro de 1895, na França. Os irmãos Auguste e Louis Lumière deram início ao então grande marco mundial do desenvolvimento da reprodução do movimento.

Utilizado como meio de entretenimento ou meio cultural, o cinema é também um instrumento poderoso capaz de comover, expressar sentimentos e representar a realidade, mostrando lugares e culturas e transmitindo histórias de diversos gêneros. Hoje o cinema se popularizou devido ao seu poder de 
comunicação, sendo apreciado por espectadores de diversas idades, classes e culturas. Assim, o cinema tornou-se um meio influente para a divulgação de fatos e ideias, ou seja, além de cultural, tornou-se um produto comercial.

\subsubsection{A sétima arte}

O cinema é uma das representações artísticas mais populares do mundo. Como as demais obras artísticas, o cinema desperta nos espectadores os mais variados sentimentos, incluindo alegria, tristeza e raiva. Desde o início de sua produção, a sétima arte está entre as formas mais prazerosas e populares de lazer.

Em cada filme, há uma proposta. Os irmãos Lumière, idealizadores do cinema enquanto técnica, tiveram, em um primeiro momento, a intenção de captar a realidade em movimento sem nenhuma interferência humana, mostrando cenas de famílias, de fábricas, de trens e até mesmo do almoço de um bebê (INÁCIO, 2012).

De acordo com Canudo (1995), a expressão sétima arte é cunhada no ano de 1912, em um manifesto denominado Manifesto das Sete Artes, como forma de registrar acontecimentos ou de narrar histórias. O cinema passa, então, a ser chamado de sétima arte desde a publicação desse manifesto, ocorrida só no ano de 1923.

De acordo com o Manifesto das Sete Artes, estas consistem em: 1. Arquitetura, 2. Escultura, 3. Pintura, 4. Música, 5. Dança, 6. Poesia e 7. Cinema.

\subsubsection{Ficção versus realidade}

É preciso discutir a diferença entre um filme de ficção e um documentário. Um documentário tem como intenção retratar a verdade sobre certo fato ou acontecimento. No entanto, a ficção não existe sem a realidade, pois o cinema de ficção não existiria sem que a verdade estivesse em pauta.

6 Disponível em: <http://fgimello.free.fr/enseignements/metz/textes theoriques/canudo.htm>. Acesso em: 09 jun. 2012.
Silverio (2013) considera que a fronteira entre realidade e ficção vem se tornando cada vez menor. Justifica esse posicionamento ao reconhecer que a indústria cinematográfica, atualmente, transgride os limites entre o real e o imaginário ao refletir lutas, vitórias, derrotas, sonhos, realizações e esperanças. Além disso, desvenda fantasias, angústias, injustiças e felicidades. Desse modo, ultrapassa as fronteiras entre o real e o imaginário.

O cinema é, ao mesmo tempo, realidade e ilusão, pelo fato de não existir filme que seja desprovido do real ou totalmente ilusório. Por essa razão, pode-se afirmar que, em um filme, existem várias interferências da realidade concreta (SILVERIO, 2013).

2.2.3 A religião como tema cinematográfico

O cinema trabalha, de modo implícito ou explícito, com um vocabulário religioso em forma de dramas, mitos e perguntas existenciais ao tratar da incansável busca humana por pertencimento, reconhecimento, orientação e sentido (HERRMANN, 2001 apud ADAM, 2012). Muitos são os filmes relacionados à religião, com forte base bíblica, que as telas de cinema já mostraram.

O cinema é uma expressão religiosa tanto pelo seu conteúdo quanto pelo rito que se desdobra em torno dele. Para Adam (2012), o ato de ir ao cinema e assistir a um filme tem algo de litúrgico, de ritual, explicando que a religião se expressa por meio de conteúdos, mas, sobretudo, por meio de ritos. Entende que se deve pensar o cinema como um culto, um rito, por meio do qual nos encontramos com quem comunga de uma mesma crença e também com o transcendente, com o mistério da vida que vai além da capacidade de absorção humana. 


\subsubsection{A análise fílmica}

A análise fílmica pode ser feita de diversas formas, pois depende do ambiente onde é realizada. Também poderá ser diferente devido à interferência do conhecimento, da experiência e do talento de quem a realiza, bem como da intenção pretendida com o texto. Esse procedimento é denominado de análise fílmica ou de crítica de cinema, podendo se enquadrar como um comentário, uma resenha ou simplesmente um jornalismo cultural (FRANÇA, 2002).

Penafria (2009) entende que, mesmo não existindo uma metodologia universalmente aceita para se proceder à análise de um filme, é possível reconhecer que essa tarefa implica duas etapas importantes: decompor, ou seja, descrever, e, em seguida, estabelecer e compreender as relações entre esses elementos decompostos, ou seja, interpretar. A partir disso, Penafria (2009) propõe os seguintes procedimentos: 1) análise textual; 2) análise de conteúdo; 3) análise poética; e 4) análise da imagem e do som.

Já para França (2002), a análise filmica apresenta seis fases ou etapas. $\mathrm{Na}$ primeira fase, o analista assiste ao filme como um espectador comum; na segunda fase do trabalho, que inicia ao mesmo tempo que a primeira, isto é, no início da projeção, o analista estará entregue à experiência pessoal que o filme lhe proporciona; na terceira fase do processo, o analista assistirá ao filme novamente, dedicando atenção especial à observação dos diversos elementos filmicos; em seguida, irá formular hipóteses sobre o filme, sobre seu projeto e sobre o diálogo que ele estabelece com o mundo; na quinta etapa do trabalho, o analista assiste o filme pela terceira vez, agora para verificar (confirmar, refutar ou corrigir) as hipóteses levantadas na fase anterior; e na sexta e última fase, ocorre a redação do texto final da análise fílmica, etapa de orientação e desenvolvimento de todas as anotações feitas desde o início do processo e de organi- zação das ideias dentro da estrutura do esboço do sistema, feito na quarta fase $\mathrm{e}$ verificado na quinta.

\section{Método de pesquisa}

Por meio de uma postagem no $b \log ^{7}$ do Arquivo Público do Estado do Rio Grande do Sul (APERS), onde foram selecionados e indicados 30 filmes que abordam a temática arquivo e biblioteca, buscou-se atentar para as possibilidades de pesquisa. Após a identificação dos filmes com maiores incidências de resultados, foi utilizado, como segundo critério de seleção, a presença da temática religiosa como pano de fundo. Tal escolha se deveu ao fato de que, de modo geral, a religião está relacionada ao mistério, ao segredo e ao desconhecido, termos que poderiam ser aplicados também aos arquivos, pelo menos de acordo com o senso comum.

A partir desses critérios, foram encontrados cinco filmes que relacionam arquivos e religião: "O código Da Vinci" (2006), "Em nome do Pai" (1993), "O Nome da Rosa" (1986), "Anjos e Demônios" (2009) e "Os Arquivos Secretos da Inquisição" (2006). Optou-se, então, por trabalhar com dois destes filmes: "O Nome da Rosa" (1986) e "Anjos e Demônios" (2009), analisados a seguir.

\section{Discussão dos resultados}

Nesta seção, são analisados os filmes selecionados para estudo.

\section{1 "Anjos e Demônios"}

Lançado em 2009, “Anjos e Demônios" é um filme que consiste em uma história policial de Dan Brown, baseada nas divergências entre a ciência e a religião, dirigido por Ron Howard. No filme, é abordada uma seita conhecida como Illuminati e sua relação com

\footnotetext{
7 Blog da APERS. Disponível em: <http://arquivopublicors.wordpress. com/2013/01/02/divulga-apers-2013/divulga-logo-vert-2>. Acesso em 30 jan. 2013.
} 
a Igreja Católica, misturando, dessa forma, ficção com realidade, pois acreditase na existência da seita dos Illuminati, formada de grandes nomes mundiais, que pretendiam dominar o mundo. $\mathrm{O}$ filme traz o relato de como é realizada a escolha de um novo Papa, o líder da Igreja Católica. Nele, o professor de simbologia de Harvard, Robert Langdon (Tom Hanks), é chamado para desvendar mistérios e símbolos que envolvem um assassinato em um importante centro de pesquisa, o Centro Europeu de Pesquisa Nuclear (CERN), na Suíça. Com a morte do Papa, ocorre o conclave, uma reunião de cardeais para a eleição do novo líder da Igreja Católica.

No filme, os Illuminati são apresentados como uma antiga seita constituída de físicos, filósofos, matemáticos e astrônomos que buscam a verdade científica e que, desde o século XVII, vêm ameaçando acabar com a Igreja Católica e, assim, dominando o mundo.

A partir do símbolo (Figura 1), Langdon desconfia que o assassinato no CERN tem ligação com os Illuminati e que estes pretendem atacar o Vaticano, consumando sua vingança prometida há séculos.

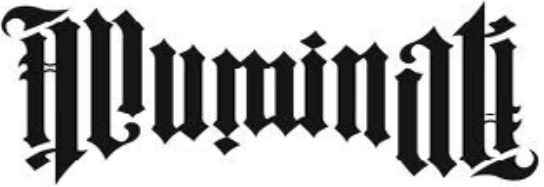

Figura 1 - Símbolo ambigrama, marca Illuminati.

A filha de um cientista assassinado de forma misteriosa, Vittoria Vetra (Ayelet Zurer), ajuda então o professor Langdon a desvendar os segredos que envolvem a trama. Após o sequestro de quatro dos principais cardeais que concorrem à eleição para o cargo do novo Papa, o camerlengo Patrick McKenna (Ewan McGregor) ajuda a desvendar aquilo que é escondido dentro do Vaticano.

\subsection{1 $\mathrm{O}$ arquivo}

Logo no início do filme, o espectador já tem contato com os arquivos quando o professor Robert Langdon fala sobre sua solicitação de acesso ao Arquivo do Vaticano. O professor Langdon está escrevendo um livro que trata da simbologia da Igreja e aborda, em uma de suas partes, os Illuminati. Para que pudesse concluir a parte de número dois de seu livro, ele precisaria ter acesso ao Arquivo do Vaticano para realizar algumas pesquisas - o Arquivo do Vaticano armazena desde obras de artes, como telas, quadros e esculturas, até livretos, livros e documentos que envolvem a religião.

Para Bellotto (2004), arquivos, bibliotecas, museus e qualquer tipo de centro de documentação são responsáveis pelo processo de recuperar a informação, em benefício da divulgação científica, tecnológica ou cultural. Sobre os fundamentos arquivísticos, no caso do Arquivo do Vaticano, salientase a utilização de mecanismos modernos e eficientes para controlar unidade, temperatura e oxigênio do ar. Também é mostrada a preocupação com a segurança do acervo. Segundo o site $e^{8}$ do Arquivo do Vaticano, seu acervo é classificado em mais de 600 fundos, sendo dividido em museu e biblioteca. Dessa forma, houve uma preocupação dos produtores do filme em, dadas as condições reais, de misturar a ficção com aquilo que está posto como vantagem de realidade, o que, indiretamente, eleva o trabalho realizado naquele arquivo do ponto de vista arquivístico, já que tem um correspondente fora das telas.

A trama acontece simultaneamente em Roma, e, para desvendar segredos e impedir que aconteça algo com a Igreja Católica, é utilizado o Arquivo com a finalidade de buscar informação a fim de evitar um trágico acontecimento para a comunidade Católica. 


\subsection{2 $\mathrm{O}$ acesso}

O acesso ao Arquivo do Vaticano ocorre por meio de uma autorização escrita. Qualquer pessoa pode solicitá-lo, mas, por se tratar de um Arquivo Secreto, o acesso é para poucos. A autorização é concedida pelo Curador, pelo Conselho de Bibliotecários do Vaticano ou pelo líder da Igreja Católica, o Papa.

Destaca-se nas falas de Langdon o pedido, indireto, de acessar aos arquivos. Sua defesa por esta concessão o faz utilizar argumentos sobre o funcionamento das normas da Igreja, indicando que se trata de um especialista e conhecedor dos detalhes que envolvem a liberação do acesso. Com a morte do Papa, para ter acesso ao Arquivo do Vaticano, Langdon procura o camerlengo, o qual libera o acesso ao Arquivo, pedindo que tenha cuidado com os tesouros da Igreja.

Por conter em seu interior vários tipos documentais (textos de diversos escritores e obras de diversos artistas), o Arquivo do Vaticano é mantido totalmente isolado e seu acesso é restrito, sendo liberado apenas com autorização via decreto das autoridades competentes. Na sequência de diálogos entre os "mocinhos" do filme (Langdon e Vittoria), isso fica mais claro quando comentam sobre um livro escrito por Galileu que estaria guardado no local. No entanto, o respeito pelo documento que é localizado no acervo é perdido no final do encontro.

Embora o casal use pinças e luvas para mexer nos documentos, este cuidado é totalmente desqualificado quando, no final da ação, há uma atitude extremista por parte de Vittoria, que, apoiada por Langdon, retira uma página, realizando um furto. A ideia de Langdon inicialmente era copiar o conteúdo da página; contudo, ele acaba concordando com o furto ao dizer: "é, temos pouco tempo".

\subsubsection{Preservação e conservação}

O filme mostra que o Arquivo do Vaticano, além de ter uma rigoro- sa norma de acesso, contempla vários mecanismos de preservação aos documentos. Pensando no monitoramento e na segurança do acervo, conta com câmaras, controle de nível de oxigênio e isolamento em relação ao meio externo. A segurança do local é utilizada como uma advertência ao pesquisador quanto à sua saúde, uma vez que as câmaras são muito bem fechadas e têm vácuo parcial; porém, é mais do que isso: trata-se de um aviso de que qualquer situação curiosa ou duvidosa será coibida em função da presença, do lado de fora, do segurança. Este cuidado extremado se justifica dentro de uma perspectiva arquivística de conservação.

Para Richter e colaboradores (1997, p. 91), a conservação consiste um "conjunto de procedimentos e medidas destinados a assegurar a proteção física dos arquivos contra agentes de deterioração". O manuseio dos documentos ocorre, assim, por meio do uso de luvas e pinças, para evitar a danificação do documento, pois são documentos antigos, que devem ser manuseados com muito cuidado.

Como já fora comentado, durante o transcorrer da trama, a acompanhante do professor Langdon, Vittoria Vetra, arranca a página do livreto escrito por Galileu por restar pouco tempo para evitar a morte de um dos principais cardeais. Sob a perspectiva da conservação, este é um ato gravíssimo, pois, como se trata de um documento de arquivo antigo, seria preciso proceder a uma restauração para colocar a página arrancada no lugar.

\section{2 "O Nome da Rosa"}

Lançado em 1986, "O Nome da Rosa" conta uma história que ocorre em um mosteiro na Itália, entre 1216 e 1334, aproximadamente, quando o Papa era João XXII. O mosteiro continha o maior acervo cristão do mundo. Neste local, o acesso era restrito, devido às diversas obras armazenadas na biblioteca, como o espaço é designado no filme. 
Durante o filme, acontecem vários crimes dentro do mosteiro. É por causa dos assassinatos que é chamado um monge franciscano, William de Baskerville (Sean Connery), para investigar esses crimes. As mortes estavam a perturbar todos, pois os mortos eram encontrados com a língua e os dedos roxos. No decorrer da trama, é desvendada a causa da morte: ao folhar (manusear) os livros da biblioteca do mosteiro, as pessoas eram envenenadas. Dessa forma, quem tinha acesso à informação contida nos documentos/livros morria antes mesmo que contasse a outro qual era seu conteúdo.

O livro envenenado em destaque na trama fora escrito por Aristóteles e trazia informações sobre o riso, sugerindo que Jesus também compartilhava dessa atitude. Tal forma de ver a vida, com riso e graça, era visto como algo errado pelos monges do mosteiro, para quem o riso estava ligado ao pecado, contradizendo o conteúdo do livro, que via a comédia como um instrumento da verdade.

William de Baskerville utilizava, então, a ciência e a razão para solucionar os crimes ocorridos, o que aborrecia o Inquisidor Bernardo Gui (Fahrid Murray Abraham). A trama ocorre no período da Inquisição, onde eram condenados, torturados e mortos os que estavam contra os dogmas da Igreja.

\subsection{1 $\mathrm{O}$ arquivo}

Neste filme, o arquivo propriamente dito é chamado de biblioteca, local em que estão armazenados pergaminhos e livros com textos científicos e filosóficos, tidos como proibidos pelos monges da Igreja por se tratar de assuntos que contradiziam a opinião e visão da Igreja.

Para Bellotto (2004), documentos de arquivos são produzidos tanto por uma entidade física ou jurídica quanto por uma pessoa ou família, justificando a sua existência para fim de comprovações, independente do suporte onde está armazenada a informação. Já os docu- mentos de bibliotecas, conforme Bellotto (2004), são resultados de criações/ produções artísticas e pesquisas, que têm como objetivo difundir informações técnicas, científicas ou humanísticas de uma forma que possa ensinar ou instruir, independentemente do suporte armazenado. Uma das principais diferenças entre os documentos de arquivos e de bibliotecas é a quantidade de exemplares, maior nas bibliotecas. No filme, no entanto, percebe-se que havia um trabalho de ilustração sendo realizado por monges copistas, o que aponta para uma perspectiva de unicidade dos documentos ali guardados.

Embora o filme, produzido em 1986, lide com um tempo distante do nosso, alguns cuidados poderiam ter sido tomados no intuito de mostrar o quanto as informações eram preciosas, mesmo em tempos longínquos. A cena transcrita a seguir, vivida pelos dois personagens principais que investigam os crimes, mostra o quanto eram importantes essas escrituras mantidas sob a custódia dos monges no espaço junto ao mosteiro:

01:07:35: [Entram na Biblioteca através do porão do mosteiro]

Willian: Adso, você percebe que estamos numa das maiores bibliotecas da cristandade?

Adso: Como vamos achar o livro?

Willian: Com calma. Com muita calma.

Esse trecho informa ao espectador que não se trata de uma biblioteca em sua concepção atual, onde existem livros que estão replicados aos milhares em outras bibliotecas, mas de um espaço exclusivo, com obras raras e com um grande número de volumes. Um desses documentos era uma obra escrita por Aristóteles, um documento que expressava o prazer pela comédia.

O roteirista do filme, baseado no livro homônimo de Umberto Eco, transmite ao público a ideia de que a obra de Aristóteles não deveria ser lida pelo fato de que poderia fazer com que as pessoas 
duvidassem dos Evangelhos, e, como forma de prevenir a divulgação dessa informação, o Frei colocava veneno mortal em suas folhas, justamente no local em que os dedos de quem leria o material tocariam o papel. A dúvida sobre a existência de determinada obra (a de Aristóteles) é levantada na discussão entre William e Jorge, denotando que o segredo em relação ao acervo da biblioteca não traz certezas quanto àquilo que o espaço contém. Em termos estruturais, a biblioteca era dividida em diversas salas, e o bibliotecário Venerável Jorge de Burgos (Feodor Chaliapin Jr.) era o responsável pela massa documental. O espaço apresentava uma forma de labirinto, com armadilhas, para que quem tivesse acesso ao local não conseguisse sair facilmente, ficando impedido, assim, de divulgar o conhecimento adquirido na biblioteca do mosteiro. Nota-se que as nomenclaturas utilizadas em ambos os filmes são equivocadas, pois o responsável pelo Arquivo do Vaticano (de "Anjos e Demônios") e pelo arquivo existente dentro do mosteiro (em "O Nome da Rosa"), em ambos os casos, é chamado de bibliotecário, e não de arquivista, como seria o correto. Sem dúvida, a Biblioteconomia e a Arquivologia mantêm estreita relação; apresar disso, cada uma tem suas próprias características.

Richter e colaboradores (1997) apontam algumas semelhanças entre essas duas áreas: tanto os arquivistas quanto os bibliotecários têm o objetivo de tornar disponível a informação contida nos materiais sob sua custódia. Além disso, tanto arquivistas quanto bibliotecários se preocupam com as atividades ligadas à preservação e conservação do acervo pelo qual são responsáveis, tendo em seu currículo acadêmico disciplinas relacionadas à defesa da memória.

\subsubsection{O acesso}

O maior responsável pelo arquivo do mosteiro era o Abade (Michael Lonsdale), junto com seu assistente, o bibliotecário Venerável Jorge de Burgos (Feodor Chaliapin Jr.). Devido à biblioteca estar estruturada em uma torre dentro do mosteiro, tinha diversas formas de acesso, com códigos secretos.

Ao longo do filme, fica claro que apenas essas duas personagens tinham acesso a todos os documentos. O Venerável era quem dava autorização de acesso e liberação para pesquisa e consulta nos documentos sob a custódia do mosteiro. A esse respeito, William de Baskerville dialoga com Adso sobre a dificuldade de entrar em contato com as informações:

01:08:47 [Biblioteca]

Willian: Quantas salas mais? Quantos livros mais?

Willian: Ninguém deveria ser proibido de consultar esses livros.

Adso: Talvez eles sejam considerados preciosos e frágeis demais.

Willian: Não é isso, é porque aqui contém uma sabedoria diferente da nossa e ideias que fariam por em dúvidas a palavra de Deus. E a dúvida é inimiga da fé.

Nesse trecho, fica evidente, pela voz do mais experiente dos dois investigadores, que o segredo está ligado aos perigos do conteúdo do acervo. William chama de "sabedoria diferente" esta que está sendo negada ao grande público. Sob uma perspectiva arquivística, tratase de informações arquivísticas com algum grau de sigilo, que não podem ser acessadas por qualquer pessoa. No caso do mosteiro, apenas alguns tinham a permissão para acessar os manuscritos. $\mathrm{O}$ cuidado extremo indica uma estratificação: aqueles que podem e aqueles que não podem ler.

\subsubsection{Preservação e conservação}

A trama "O Nome da Rosa" retrata uma época antiga, entre os séculos XIII e XIV, em que havia poucos recursos e ferramentas para a conservação e preservação dos documentos - estudos mais aprofundados no que diz respeito a 
políticas de preservação e conservação surgiram somente mais tarde.

De acordo com Cassares (2000, p. 12), a preservação é "um conjunto de medidas e estratégias de ordem administrativa, política e operacional que contribuem direta ou indiretamente para a preservação da integridade dos materiais". Analisando o filme, não é possível identificar nenhum procedimento explícito de preservação. Apenas sabe-se que a biblioteca ficava em uma torre, o que sugere um local com paredes de pedra e, portanto, grossas (evitando, assim, a grande variação de temperatura), pouco úmido (por ser distante do chão) e escuro (pela ausência de muitas aberturas). No entanto, há indícios de muita poeira no local, pois o acesso era restrito, não havendo a possibilidade de limpeza frequente, $o$ que pode causar danos à documentação.

A insalubridade do local para pessoas e documentos, contudo, salta aos olhos quando, em determinado momento da trama, dentro da biblioteca, aparece um rato. A infestação por roedores, considerados uma praga para documentos em suporte papel, dá a certeza de que esse acervo não contempla maiores cuidados considerando-se as perspectivas atuais sobre preservação e conservação. roedores esse respeito, Cassares (2000, p. 17) afirma que "os roedores e os fungos, cuja presença depende quase que exclusivamente das condições ambientais reinantes nas dependências onde se encontram os documentos".

Acidentalmente, no final do filme, a biblioteca pega fogo, sendo o acidente provocado pelo próprio responsável. Desesperado, a fim de preservar parte da documentação e das informações que estavam no local, William de Baskerville consegue resgatar alguns livros, trazendo-os consigo e salvando -os do incêndio, o que indica que, mesmo sendo uma época na qual pouco se discutia a preservação de documentos, algumas pessoas tinham a consciência da importância que um acervo documental tem tanto para comprovação de informações quanto para a conservação da história de um povo.

\section{Conclusão}

Os pontos ora apresentados sobre a relação entre a arquivologia e o cinema refletem a forma como são abordados os arquivos e o profissional arquivista na sétima arte. Com a análise fílmica de "Anjos e Demônios" e "O Nome da Rosa", foi possível perceber que são poucos os conhecimentos transmitidos para o público geral a respeito das técnicas utilizadas pelos arquivistas nos dias de hoje, tanto no que diz respeito à preservação e conservação quanto no que concerne ao armazenamento dos documentos, faltando um reconhecimento maior dos diretores sobre as questões que envolvem os arquivos.

Um estudo mais aprofundado poderia auxiliar a evitar a transmissão de uma visão distorcida sobre o profissional arquivista inserido em ambiente de trabalho. Além disso, a partir das análises, é perceptível uma mistura entre o papel do arquivista e do bibliotecário, bem como certa confusão com relação a seus espaços de trabalho. Apesar de ambas serem ciências afins, cada uma tem suas especificidades e, por isso, devem ser tratadas de modo a respeitar seus estudos e avanços particulares.

Os resultados desta pesquisa indicam que essa distorção de funções profissionais é apenas um dos aspectos a considerar, já que a evolução da produção cinematográfica de 1986 para a dos anos 2000 aponta para um maior reconhecimento da importância conferida às questões que envolvem os arquivos, tendo o acervo sigiloso do Vaticano em "Anjos e Demônios" um estatuto de importância efetivamente maior que o de "O Nome da Rosa". Ademais, a exemplo do que mostra "Anjos e Demônios", atualmente os arquivos são bem mais equipados, com sistemas de segurança, políticas de preservação e políticas de acesso que fazem o profissional arquivista ganhar espaço junto ao mercado de trabalho.

Em relação à importância do arquivo para a sociedade, ambos os fil- 
mes fazendo do arquivo e da biblioteca o cenário principal, mostrando que $o$ uso da informação contida no acervo documental pode desvendar mistérios e somar conhecimento. $\mathrm{O}$ arquivo é um lugar onde se encontra a história (seja de um povo, de uma instituição ou de uma pessoa), e através é por meio dela que se pode celebrar a memória. No filme "Anjos e Demônios", pode-se notar nitidamente o quanto o Arquivo do Vaticano é importante para desvendar enigmas sobre os crimes que estavam acontecendo na Santa Sé.

Por meio deste estudo, pode-se perceber claramente a forma como são abordados os arquivos e o profissional que deles cuida nas produções cinematográficas. Espera-se que, em futuras produções, haja uma evolução da abordagem acerca dessa temática, que permita transparecer, de uma forma mais clara, as funções do profissional de arquivo e suas atribuições dentro de um espaço com acervo arquivístico.

\section{Referências}

ADAM, Júlio Cesar. Da ficção científica para a ficção religiosa: ideias para pensar o cinema de ficção científica como o culto da religião vivida. Horizonte, Belo Horizonte, v. 10, n. 26, p. 552-565, abr./jun. 2012.

ANJOS e demônios. Produzido por John Calley, Brian Grazer, Ron Howard. Dirigido por Ron Howard. Trilha Sonora: Hans Zimmer. 1 DVD (140min).

ARQUIVO NACIONAL, Dicionário brasileiro de terminologia arquivística. Rio de Janeiro: Arquivo Nacional, 2005.

Legislação arquivística. Rio de Janeiro: Arquivo Nacional, 2008. Disponível em: < www.conarq.arquivonacional.gov.br > Acesso em: 15 abr. 2013.

BAUER, Martin; GASKELL, Geor- ge. Qualidade, quantidade e interesses do conhecimento: evitando confusões. In: Pesquisa qualitativa com texto, imagem e som: um manual prático. 4.ed. Petrópolis, RJ. Editora Vozes, 2002.

BELLOTTO, Heloísa Liberalli. Arquivos permanentes: tratamento documental. 2. ed. Rio de Janeiro: Editora FGV, 2004.

CASSARES, Norma Cianflone. MOI, Cláudia. Como fazer conservação preventiva em arquivos e bibliotecas. São Paulo: Arquivo do Estado e Imprensa Oficial, 2000.

DUARTE, Jorge; BARROS, Antonio (orgs.). Métodos e técnicas de pesquisa em comunicação. São Paulo: Atlas, 2005.

FRANÇA, André Ramos. Das teorias do cinema à análise fílmica. Dissertação (Mestrado em Comunicação e cultura) - Câmara de Ensino de PósGraduação e Pesquisa. Universidade Federal da Bahia, Salvador, 2002. Disponível em: <http://www.andrefranca. com/andre/dissertacao.pdf $>$. Acesso em: 09 jun. 2013.

GIL, Antonio Carlos. Métodos e técnicas de pesquisa social. São Paulo: Atlas, 2007.

INÁCIO, Gledson dos Santos. O surgimento do cinema: personagens $\mathrm{e}$ representações. 2012. Disponível em: $<$ http://pibid-historiaufs.blogspot.com. br/2012/05/o-surgimento-do-cinema -personagens-e.html.>. Acesso em: 10 maio 2013.

LUCHER, Marciéle Peuckert. Os arquivos nos livros: a visibilidade da arquivologia na literatura ficcional. Santa Maria. UFSM. 2013.

O NOME da rosa. Diretor: Jean-Jacques Annaud. Ano 1986. 1 DVD (118min).

PENAFRIA, Manuela. Análise de filmes: conceitos e metodologia(s). 2009. CONGRESSO SOPCM, 6, Anais... 
Disponível em: <http://www.bocc. ubi.pt/pag/bocc-penafria-analise.pdf.> Acesso em: 2 jun. 2013.

RICHTER, Eneida Izabel Schirmer, GARCIA, Olga Maria Correa, PENNA, Elenita Freitas. Introdução à arquivologia. Santa Maria : UFSM, 1997. 102 p.

RONDINELLI, Rosely Curi. Gerenciamento arquivístico de documentos eletrônicos: uma abordagem teórica da diplomática arquivística contemporânea. Rio de Janeiro: Editora FGV, 2002.

ROUSSO, Henry. $O$ arquivo ou o indício de uma falta. Estudos Históricos. Rio de Janeiro, $\mathrm{n}^{\mathrm{o}}$ 17, 1996. 7 p. Disponível em: <www.cpdoc.fgv.br > . Acesso em 15 nov. 2011.

SANTOS, Cristian José Oliveira. Os arquivos das primeiras prelazias e dioceses brasileiras no contexto da legislação e práticas arquivísticas da Igreja Católica. Dissertação (Mestrado em Ciências da Informação) - Programa de Pós-Graduação em Ciências da Informação. Universidade de Brasília, Brasília, 2005.

SILVERIO, Alessandra. Filme: realidade ou ficção? Disponível em: $<$ http:// www.mnemocine.com.br/aruanda/silverioficcaoedoc.htm>. Acesso em: 4 jun. 2013. 